UDC 81'42:(047)

Submitted: 29.05.2016

LBC 81.055.515

Accepted: 14.12.2016

\title{
EXPRESSIVE MEANS IN THE NEWS MEDIA TEXTS ON ECONOMIC ISSUES IN THE ASPECT OF SPEECH IMPACT
}

\author{
Nadezhda M. Stetsenko \\ Donetsk National Technical University, Donetsk
}

\begin{abstract}
The article is devoted to the urgent problem of linguistic interpretation of news media texts. Various methods of expressing news media texts of economic subjects produced on the websites of news agencies are considered. Based on the classification proposed in the scientific literature two groups of expressive means of modern mass media are distinguished: 1) expressive means that contribute to the greater expressiveness of the material presented without disrupting the overall objectivity of the news (compression of the text when the fact is stated, transferring the focus of attention from the subject of the action or state to the semantically secondary component of the situation, utterances expressing social appraisal, text elements that indicate the presence of the author in the situation, the logical elements that model the situation of reflection, general language metaphors is described);2) expressive means that violate the neutrality and objectivity of informing speech, emphasizing the personal author's position to the published facts. The expressive means of the second group are characterized in detail, the material of the news reports of the sites of Ukrainian news agencies shows that among the evaluative elements of news media texts of economic subjects there are dominant usual expressions: emotional-evaluative words, colloquial words, vernaculars, and expressions with a pronounced sign of occasionality: ironic utterances, precedent phenomena, individual-author's metaphors, quotes of mediapersons.

Key words: mass media, news media text, creation of expression, expressive, evaluative element of text, affecting function.
\end{abstract}

\section{ЭКСПРЕССИВНЫЕ СРЕДСТВА НОВОСТНЫХ МЕДИАТЕКСТОВ ЭКОНОМИЧЕСКОЙ ТЕМАТИКИ В АСПЕКТЕ РЕЧЕВОГО ВОЗДЕЙСТВИЯ}

\author{
Надежда Михайловна Стеценко \\ Донецкий национальный технический университет, г. Донецк
}

\begin{abstract}
Аннотация. Статья посвящена актуальной проблеме лингвистической интерпретации новостных медийных текстов. Рассматриваются различные приемы экспрессивизации новостных медийных текстов экономической тематики, продуцируемых на сайтах информационных агентств. С опорой на предложенные в научной литературе классификации выделены две группы экспрессивных средств современных масс-медиа: 1) экспрессивные средства, которые нарушают нейтральность и объективность информирующей речи, подчеркивая личностную авторскую позицию по отношению к публикуемым фактам; 2) экспрессивные средства, которые способствуют большей выразительности изложенного материала, не нарушая в целом объективности новостей (компрессия текста при констатации факта; перенесение фокуса внимания с субъекта действия или состо- яния на семантически второстепенный компонент ситуации; высказывания, выражающие социальную оцен궁 ку; элементы текста, которые указывают на присутствие автора в описываемой ситуации; логические элеменi ты, моделирующие ситуацию размышления; общеязыковые метафоры). Подробно охарактеризованы экспрессивные средства второй группы, на материале новостных сообщений сайтов украинских информационных агентств показано, что среди оценочных элементов новостных медийных текстов экономической тематики доминируют узуальные экспрессивы: эмоционально-оценочные слова, разговорные слова, просторечие, а также экспрессивы, имеющие выраженный признак окказиональности: ироничные высказывания, прецедентные феномены, индивидуально-авторские метафоры, цитаты медиаперсон.
\end{abstract}


Ключевые слова: СМИ, новостной медиатекст, экспрессивизация, экспрессив, оценочный элемент текста, воздействующая функция.

\section{1}

Значительную часть новостей масс-медиа занимает экономическая и финансовая информация, от корректности и адекватности освещения которой зависит решение ряда проблем в жизни современного человека и общества в целом. В связи с этим чрезвычайно актуальным заданием для медиалингвистики представляется исследование лингвистической интерпретации новостных медийных текстов экономической тематики.

Особенности новостных медиийных текстов обусловлены стремлением к объективности и нейтральности излагаемой информации. Отсюда ряд специфических языковых черт, диктуемых их фунционально-жанровой принадлежностью: высокая степень клишированности, отсутствие лексических единиц с развитым коннотативным компонентом значения, большое количество глагольных словосочетаний, безличных форм и т. д. (3. Вайшенберг, Ю.С. Воротникова, Ф.Т. Грозданов, Т.Г. Добросклонская, К.Д. Кирия, М.Л. Ковальчукова, А.В. Колесниченко, О.Р. Лащук, Ю.В. Шемелина и др.).

Вместе с тем исследования современной медиаречи убедительно доказывают, что новостным медиатекстам в неменьшей степени, чем прочим жанровым разновидностям медиатекстов, присущ воздействующий потенциал (Т.С. Дроняева, Н.Н. Панченко, Т.А. Присяжнюк, А.А. Негрышев, А.Ш. Сафаргалина, С.И. Сметанина, Н.С. Цыбикова и др.). Так, Т.С. Дроняева утверждает, что в новостном дискурсе представлено достаточное количество экспрессивных средств, которые способствуют проявлению субъективности, то есть преодолению жанрово обусловленной объективированности новостного (информационного) текста в целях воздействия на читателя [Клушина, 2003]. Соглашаясь с этим мнением, А.А. Негрышев отмечает: «Стилистическая нейтральность новостей отнюдь не свидетельствует о преобладании стандарта над экспрессией» [Негрышев, 2013, с. 44].

Новостные медийные тексты экономической тематики, которые продуцируются на сайтах информационных агентств, в силу особенностей их содержания и распространения, представляются наиболее «стандартизованными» среди медиатекстов других тематических доминант, лишенными каких-либо экспрессивов; однако реалии современной массовой коммуникации подтверждают, что экспрессия не чужда и новостям экономики.

Объектом нашего исследования стали новостные сообщения русскоязычных версий интернет-сайтов украинских информационных агентств УНИАН (Украинское независимое информационное агентство новостей), «Укринформ» (Украинское национальное информационное агентство), «Интерфакс-Украина» (Украинская медиакомпания в структуре международной информационной группы Interfax Information Services), УНН (Украинские национальные новости). Предметом исследования являются экспрессивные средства в новостных заметках раздела «Экономика». Цель работы: исследование экспрессем новостных медиатекстов экономической тематики в прагматическом аспекте.

\section{2}

Несмотря на многочисленность лингвистических публикаций, посвященных изучению категории экспрессивности (И.В. Арнольд, Ш. Балли, В.В. Виноградов, Е.И. Галкина-Федорук, В.Д. Девкин, М.Н. Кожина, Н.А. Лукьянова, В.Н. Телия, В.И. Шаховский и др.), в науке не сформировано единого мнения о сущности данного понятия. Как объект изучения эта специфическая языковая категория сочетает различные аспекты оценочности, эмоциональности, образности, интенсивности и других категорий. В некоторых исследованиях понятие экспрессивности используется в значении эмоциональной оценочности (Ш. Балли, В. Матезиус, Р.О. Якобсон и др.). В других работах эмотивность называется составной частью экспрессивности (В.И. Шаховский, Н.А. Лукьянова и др.). Согласимся с утверждением о том, что эмоциональность является составляющей экспрессивности, однако не обязательно связана с выражением 
чувств адресанта - «экспрессивность может пронизывать как эмоциональное, так и интеллектуальное» [Скрипак, 2013, с. 170].

В дискуссии о соотношении в экспрессиве эмоции и оценки представляется интересным мнение о том, что «экспрессивный и собственно оценочный аспекты значения слова или высказывания существуют независимо друг от друга» [Вольф, 1985, с. 42]. В то же время оценочность (заложенная в слове положительная или отрицательная характеристика объекта) и эмоциональность (отраженное в семантике слова отношение говорящего к объекту речи) как взаимосвязанные и взаимообусловленные признаки лексических единиц считаем необходимыми критериями для изучения экспрессивного потенциала медиатекстов, поскольку в «Лингвистическом энциклопедическом словаре» экспрессивность определяется как «совокупность семантикостилистических признаков единицы языка, которые обеспечивают ее способность выступать в коммуникативном акте как средство субъективного выражения отношения говорящего к содержанию или адресату речи» [Гридин, 1990, с. 591].

Для настоящего исследования отметим значимость мнения И.В. Арнольд, согласно которому экспрессивность выражается в способности текстовой информации передавать значение с увеличенной интенсивностью с целью отобразить внутреннее состояние адресанта, в результате чего текст содержит эмоциональное или логическое усиление, которое может быть или не может быть образным [Арнольд, 1975, с. 15]. Считаем обоснованной сходную точку зрения, распространенную в современных работах, посвященных исследованию экспрессии (Н.В. Аванесова, Л.И. Билан-Котельникова, Г.В. Вахитова, Н.Ф. Хасанова и др.): экспрессивность - это средство интенсификации высказывания, любое усиление содержания текста, выделение и акцентирование информации, осуществляемое самыми разнообразными способами и средствами [Хасанова, 2015, с. 107].

Следует также принять во внимание тот факт, что лингвистическим механизмом экспрессивности называют прежде всего отклонение от стереотипов в использовании языковых единиц разных уровней [Войтенко].
3

Экспрессивы в текстах современных масс-медиа анализировали в своих работах такие исследователи, как Е.Н. Дорофеева, Л.П. Дядечко, В.Г. Костомаров, Л.А. Кудрявцева, А.М. Подшивайлова, Е.В. Святчик, И.А. Филатенко, А.А. Черненко и др.

По нашим наблюдениям, случаев, когда новостной медиатекст экономической тематики содержит богатый набор экспрессивных средств, на анализируемых сайтах нет. Вместе с тем исследованный материал показывает достаточное количество разнообразных способов интенсификации высказывания и в данной функционально-жанровой разновидности медиатекстов.

Категория экспрессивности реализуется в новостном медиатексте с целью придания большей выразительности нейтрально изложенному материалу, а также служит способом выражения субъективного мнения автора о публикуемой информации. На основании установленных Л.А. Кудрявцевой моделей экспрессивизации печатных медиатекстов [Кудрявцева, 1998, с. 296], а также выделенных Т.С. Дроняевой экспрессивных средств информационного подстиля речи [Дроняева, 2003] можно выделить две группы экспрессивных средств в современных новостных медиатекстах экономической тематики.

К первой группе отнесем систему оценочных элементов, которые нарушают нейтральность и объективность информирующей речи, подчеркивая личностную авторскую позицию по отношению к публикуемым фактам:

- узуальные экспрессивы (номинативные единицы, экспрессивный характер которых понятен без какого-либо контекста: эмоционально-оценочные слова, разговорные слова, просторечие и др.);

- экспрессивы, имеющие выраженный признак окказиональности (ироничные высказывания, прецедентные феномены, индивидуальноавторские метафоры, цитаты медиаперсон и др.).

Ко второй группе отнесем экспрессивные средства, которые способствуют большей выразительности изложенного материала, не нарушая в целом объективности новостей:

- компрессия текста при констатации факта; 
- перенесение фокуса внимания;

- высказывания, выражающие социальную оценку;

- сигналы эгоцентризма автора;

- логические элементы, моделирующие ситуацию размышления;

- общеязыковые метафоры и др.

3.1. Охарактеризуем экспрессивные средства, которые подчеркивают авторскую оценку публикуемых фактов, нарушая нейтральность новостных медиатекстов экономической тематики. Преимущественное количество оценочных элементов экономических новостей сосредоточено в заголовке медиатекстов. Сильная позиция заголовка максимально используется автором публикации для привлечения внимания читателя, поэтому именно здесь сконцентрированы разнообразные приемы, обладающие воздействующим потенциалом. Отметим тот факт, что в заголовочную позицию может выноситься не фрагмент информации текста, но его вариант, интерпретированный автором. Например, заголовок Яиченюк похвастался ростом экономики в четвертом квартале 2015 года соответствует тезису текста есть первые признаки стабилизации экономики (УНИАН, 16.02.2016, 16:57).

Эмоционально-оценочные слова. Данная категория лексики представлена прежде всего прилагательными, причастиями и наречиями. В заголовочной позиции текста содержится обычно эмоциональный вариант, соответствующий нейтральному текстовому определению. Например: (заголовок) В ГФС назвали худшие в Украине АЗС / (текст) не соответствует стандартам качества (УНН, 25.02.2016, 14:33); (заголовок) КБ Южное "взбунтовалось" против нового руководителя / (текст) участники пресс-конференции собрались с целью защиты своего экс-руководителя (Укринформ, 23.02.2016, 17:14). Согласимся с выводами А.Р. Минемуллиной, исследовавшей оценочные прилагательные в текстах СМИ: в современных масс-медиа преобладают отрицательно-оценочные лексемы, что показывает преимущественно отрицательное отношение медиаавторов к описываемым явлениям современной жизни [Минемуллина, 2014, c. 168$]$.
Разговорная лексика. В новостном медиатексте разговорные элементы на фоне прочих слов становятся средством экспрессии, поскольку придают языку непринужденность, привнося в нейтральный стиль изложения элементы устного общения. Например, разговорные слова, образованные путем универбации: Минрегион вычислил «среднюю» платежку в отопительном сезоне (Укринформ, 19.02.2016, 12:33); Украина будет поставлять мясо в ОАЭ. На очереди - мед, молочка и кондитерка (Укринформ, 29.02.2016, 14:27).

Просторечная лексика. Мощным прагматическим потенциалом обладают просторечные слова, которые используются в новостной речи, поскольку демократизация языка СМИ и связанные с ней тенденции к огрублению высказывания позволяют медиаавтору реализовать более мощную, по сравнению с соответствующими им нормативными оценочными элементами, эмоциональную реакцию на происходящее. Например: (заголовок) Яворивского "достала" реклама Таможенного союза / (текст) В Верховной Раде зарегистрирован проект постановления "О запрещении политической рекламы Таможенного союза в Украине» как носящей антигосударственный характер (УНИАН, 22.02.2013); (заголовок) Кабмину рассказали, как госкомпания "прохлопала» $\$ 200$ тысяч на китайском кредите / (подзаголовок) Государственная продовольственнозерновая корпорачия Украины потратила 200 тысяч долларов на резервирование китайского кредита в сумме 1,5 миллиарда долларов (Укринформ, 18.03.2016, 15:41). Просторечие (достала, прохлопала) в заголовочной позиции выразительно демонстрирует авторское отношение к описываемым фактам.

Ироничные высказывания. Ирония признается исследователями ведущей чертой языка современных СМИ [Клушина, 2003]. По словам Е.Ю. Скороходовой, в последние годы эта стилистическая фигура стала применяться публицистами не только в развлекательных, аналитических, но и в новостных жанрах, для которых она является важным средством усиления выразительности речи [Скороходова, 2011]. При кажущейся объективированной подаче факта ирония «как одно из средств им- 
плицитного выражения оценки используется авторами публицистических текстов для воздействия на мысли и чувства аудитории» [Минемуллина, 2013, с. 20]. Например: Статус агрессора не помешал: Украина поставила РФ турбины для военных кораблей и комплектующие для самолетов (УНИАН, 25.02.2016, 14:17) - медиатекст содержит информацию о поставках Украиной комплектующих для транспортных средств России, а также факты того, что ранее украинский президент полностью запретил любое сотрудничество с РФ в сфере военно-промышленного комплекса. В заголовке иронично оценивается сложившаяся неоднозначная ситуация.

Прецедентные феномены. С целью увеличения читательского спроса «документированная» новостная информация становится материалом, который может усложняться интертекстуальными элементами, имеющими непосредственную связь с арсеналом фоновых знаний читательской аудитории. Выбор прецедентного феномена, безусловно, определяется мировоззренческой установкой адресанта и соответствующей ей оценкой события, поэтому данные единицы служат средством интерпретации новостной информации. В заголовках новостных медиатекстов экономической тематики чаще всего эксплуатируется семантическая трансформация прецедентных феноменов, при которой состав прецедентных единиц не меняется. Например: (заголовок) Внешний госдолг Украинь побил рекорд - Dragon Capital / (текст) Государственный внешний долг на конеи 2015 года вырос до исторического максимума в $\$ 43$ млрд (Укринформ, 23.03.16, 11:01) (сфера-источник - фразеологизм побить рекорд - «установить новый рекорд, выше прежнего»); (заголовок) В Фонде гарантирования подтвердили: еще два банка уйдут в небытие / (текст) Национальный банк принял решение о ликвидации и отзыве банковских лицензий двух неплатежеспособных банков $O A O$ «БГ Банк» и ПАО «Легбанк» (Укринформ, 23.02.2016, 04:33) (сфера-источник фразеологизм уйти в небытие - «умереть»). Трансформация смысла прецедентного текста в новостном заголовке является одним из проявлений языковой игры [Минемуллина, 2014, с. 169].
Индивидуально-авторские метафоры. Употребление индивидуально-авторских метафор в публицистическом тексте представляет собой способ оценки окружающего мира посредством используемых автором аналогий. Метафоризация в языке СМИ, помимо предоставления читателю объективной информации, подчеркивает авторское видение мира, а также является эффективным способом воздействия на сознание читателя. Например: (заголовок) Украина вернула Японии «хвостик» от Киотских денег / (текст) Украина вернула Японии $\boldsymbol{\epsilon 2 , 5}$ млн неиспользованных киотских средств, которые составляют примерно 1 \% от всей суммы (Укринформ, 01.03.16, 17:55); Украинский рынок акций вышел из зимы «зеленея» (Интерфакс, 28.02.2013) - в тексте речь идет о росте индексов украинского фондового рынка на площадках США. Для заголовочной метафоры автором использованы ассоциации между зеленым цветом травы (публикация сопровождается фотоизображением весенней зелени) и цветом американских денежных знаков. Подобные метафоры, по справедливому замечанию Н.Д. Бессарабовой, увеличивают информативную ценность сообщения с помощью ассоциаций, вызываемых переносным значением слова, и участвуют в важнейших функциях газетной публицистики - убеждения и эмоционального воздействия [Бессарабова, 1990, c. 23].

Цитаты медиаперсон. Установка на «документированность» новостной информации позволяет автору новостного медиатекста прибегать к цитированию в заголовке известных личностей с целью привлечения внимания потенциальных читателей. Ссылка на авторитет медиаперсоны позволяет автору использовать в цитате разнообразные стилистические фигуры, которые, по словам исследователей, выступают формой влияния на сознание реципиента [Чиж, 2012, с. 283]. Например: (заголовок) Яиенюк увидел начало выхода экономики из тени / (текст) Экономика Украины начала выходить из тени благодаря снижению налогового давления в иелом... Об этом сказал премьер-министр Украины (УНИАН, 16.02.2016, 17:15) (сфераисточник - фразеологизм выйти из тени «перестать скрываться; привлекать к себе 
внимание, становиться заметным»); (заголовок) «Медовыци» и «яичный» скандаль замешаны на политике - Павленко / (текст) «Я лично считаю, что заявления относительно яиц в Израиле и меда, который вывозился в Чехию, являются политически мотивированными», - сказал Павленко (Укринформ, 26.01.2016, 11:33) (метафора замесить скандал на политике).

Для заголовка журналисты могут сокращать цитаты, пересказывать их в соответствии со своим коммуникативным намерением, то есть знакомить реципиента, по словам Н.И. Клушиной, с квазицитатами, в которых присутствует доля достоверности, но общий смысл трансформирован под углом зрения интерпретирующего события журналиста, а не собственно автора высказывания [Клушина, 2003]; поэтому подобные заголовки имеют дополнительный оценочный смысл.

3.2. Охарактеризуем экспрессивные средства, которые способствуют большей выразительности новостных медийных текстов экономической тематики, не нарушая в целом объективности новости.

Компрессия текста при констатации факта. Новостные медиатексты, согласно особенностям информационного подстиля публицистики, используют свои, характерные для них, языковые стандарты и нормы построения текстов: констатация социально значимых фактов, а также информативное описание и повествование в них соотносятся друг с другом как причина и следствие [Дроняева, 2003]. Если же логически предшествующее событие внеязыковой действительности оформлено как информативное описание, обозначающее логический вывод, происходит компрессия текста, в результате которой языковое выражение необходимой информации берет на себя элемент текста, в обычных условиях выполняющий иную текстовую функцию. T.С. Дроняева называет такое употребление неизофункциональным, вторичным, несущим текстовую экспрессию [Дроняева, 2003]. Например: Украина на фоне трехкратного падения собственной добычи уаля из-за военных действий на Донбассе в январе 2016 года увеличила, по сравнению с январем 2015 года, потребление данного вида топлива на 33,6 \% - до 4,83 млн тонн
(УНИАН, 24.02.2016, 11:45). Инвариантная форма выражения этого содержания должна была быть такой: *Из-за военных действий на Донбассе собственная добыча угля снизилась в три раза. (В результате) потребление данного вида топлива увеличилось. Компрессия текста позволяет сделать изложение информации более выразительным.

Перенесение фокуса внимания. Фокус внимания в фактографическом высказывании новостного медиатекста может переноситься с субъекта действия или состояния на семантически необязательный, побочный компонент ситуации. Например: Bместе с тем, продлено на один год эмбарго на поставки оружся в Беларусь и замораживание активов, и запрет на поездки для четырех человек, связанных с исчезновением двух оппозиционных политиков, одного бизнесмена и одного журналиста (УНИАН, 25.02.2016, 15:39); Хотя Украина -уже один из крупнейших мировых аграрных экспортеров, она должна стать «сельскохозяйственной сверхдержавой». Об этом сказал посол США в Украине Дюсеффри Пайетт во время подписания соглашения с инвесторами с участием главы правительства А. Яценюка, передает корреспондент УНH (УНН, 24.02.2016, 10:51). При этом в публикуемом материале появляются добавочные с точки зрения объективированной подачи информации субъекты действия (ucчезновение двух оппозиционных политиков, одного бизнесмена и одного журналиста) или обозначения добавочных действий (сказал во время подписания), что позволяет сделать изображение факта более объемным.

Высказывания, выражающие социальную оценку. Такие высказывания не являются носителями индивидуально-авторской оценки, но выражают социальную точку зрения на описываемое явление. Например: Преступные группировки, занимающиеся этим видом незаконной деятельности, зарабатьвают в год от 8 до 20 млрд евро, что ставит эту деятельность в один ряд с торговлей наркотиками, людьми и оружием... приводит к человеческим жертвам и лишает беднейшие сообщества последних возможных доходов (Интерфакс, 26.02.2016, 17:23); Министерство финансов 
рассматривает возможность изъятия вкладов... на докапитализацию проблемных банков (УНН, 29.01.16, 15:53); СБУ в зоне АТО выявила злоупотребления в сфере соцвыллат переселенцам на почти 10 млн грн (Интерфакс, 19.03.2016, 15:05). Такие элементы текста (преступные группировки, незаконная деятельность и пр.) являются экспрессемами для новостных медиатекстов.

Сигналы эгоцентризма автора. Текстовые элементы, которые указывают на присутствие автора в описываемой ситуации (детали, которые моделируют ситуацию наблюдения), используются в новостных экономических текстах достаточно редко. Различные органолептические детали (изображение цвета, формы, объема, а также звука, запаха и пр.) в сообщениях информационных агентств раздела «Экономика» практически не встречаются. Однако указания на то, что видит, слышит и чувствует автор, могут быть представлены в тексте: На улице Банковой до сих пор чувствуется запах горелых шин.. Напротив них несколько машин с флагами Автомайдана. На одной из машин установлена аудиосистема, из которой раздается музыка (УНИАН, 08.04.2016, 15:29); Собеседник агентства отметил, что из изучения спроса невозможно удовлетворить вкусы всех пассажиров, особенно если они относятся к разным социиальнымм и возрастным группам (Интерфакс, $26.02 .2016,16: 15)$. Такие детали информации посредством обращения к опыту восприятия органов чувств реципиента подчеркивают ее достоверность.

Логические элементы, моделирующие ситуацию размышления. Анализ, сопоставление фактов являются строевым элементом информационно-аналитических медиатекстов, поэтому, если они присутствуют в новостных сообщениях информационных агентств, такие высказывания субъективно окрашены. Например, при помощи вставных конструкций автор может сделать некоторые акценты: Международные резервы России за прошедшую неделю с 12 по 19 февраля сократились на 0,8\% и составили 379,4 миллиарда долларов против 382,4 миллиарда долларов на 12 февраля. Следовательно, международные резервы снизились на
3 миллиарда долларов (УНИАН, 25.02.2016, 15:43); Любопьтно, что, продав Willi Food, братья продолжали полностью управлять и контролировать как операционный бизнес, так и инвестиционный портфель... Однако, похоже, Виллигеры решили вновь воспользоваться своим влиянием и вернуть компанию (УНН, 24.02.2016, 14:59).

Общеязыковые (газетные) метафоры. Особенностью употребления метафор в публицистическом стиле является тенденция к их переходу в штамп (В.Г. Костомаров, А.В. Калинин, А.Р. Минемуллина и др.). С частотой употребления часть метафорических высказываний в медиатекстах экономической тематики преобразуется в устойчивые языковые элементы, образность которых стирается: оценочная составляющая метафоры теряет свой прагматический потенциал, например: Мировые цены на золото упали (УНН, 16.11.2015, 12:01); Цены на нефть снижаются в четверг (Интерфакс, 25.02.2016, 17:51); Нефть Brent выросла до \$36,72 (Укринформ, 02.03.2016, 07:35); Гривня закрыла межбанк на отметке 26,25 за доллар (УНИАН, 22.03.2016, 18:25); Гривня уходит на выходные с курсом 27,20 за доллар (УНИАН, 26.02.2016, 17:13). Вместе с тем подобные метафоры являются средством выразительности для «сухих» экономических сводок.

4

Проведенное исследование позволяет сделать вывод об использовании в современных новостных медийных текстах экономической тематики системы экспрессивных элементов, которые не только интенсифицируют различные элементы новостной информации, но и подчеркивают авторское отношение к публикуемым фактам, увеличивая воздействующий потенциал новостного медийного текста.

\section{СПИСОК ЛИТЕРАТУРЫ}

Арнольд, И. В. Интерпретация художественного текста: типы выдвижения и проблемы экспрессивности / И. В. Арнольд // Экспрессивные средства английского языка : сб. научных трудов ЛГПИ им. А. И. Герцена. - Л. : ЛГПИ, 1975. - С. 11-20. 
Бессарабова, Н. Д. Метафора и образность газетно-публицистической речи / Н. Д. Бессарабова // Поэтика публицистики / под ред. Г. Я. Солганика. - М. : МГУ, 1990. - С. 21-34.

Войтенко, К. И. Экспрессивность как семантическая категория / К. И. Войтенко. - Электрон. текстовые дан. - Режим доступа: www.rusnauka. com/13_EISN_2013/Philologia/2_132923.doc.htm. Загл. с экрана.

Вольф, Е. М. Функциональная семантика оценки / Е. М. Вольф. - М. : Наука, 1985. - 228 с.

Гридин, В. Н. Экспрессивность / В. Н. Гридин // Лингвистический энциклопедический словарь / под ред. В. Н. Ярцевой. - М. : Советская энциклопедия, 1990.- С. 591.

Дроняева, Т. С. Информационный подстиль / Т. С. Дроняева // Язык СМИ как объект междисциплинарного исследования / под ред. М. Н. Володиной. - М. : МГУ, 2003. - Электрон. текстовые дан. Режим доступа: http://evartist.narod.ru/text12/15. htm\#3_24. - Загл. с экрана.

Клушина, Н. И. Общие особенности публицистического стиля / Н. И. Клушина // Язык СМИ как объект междисциплинарного исследования / под ред. М. Н. Володиной. - М. : МГУ, 2003. - Электрон. текстовые дан. - Режим доступа: http://evartist. narod.ru/text12/15.htm\#3_03. - Загл. с экрана.

Кудрявцева, Л. А. Моделирование экспрессивно-прагматического содержания в текстах газетной коммуникации / Л. А. Кудрявцева // Семантика языковых единиц : докл. VI Междунар. конф. (Москва, 14-15 окт. 1998 г.). - М. : СпортАкадемПресс, 1998. - C. 295-297.

Минемуллина, А. Р. Адъективная оценочная лексика в заголовке публицистического текста / А. Р. Минемуллина // Ярославский педагогический вестник. - 2014.- Т. 1, № 4. - С. 166-170.

Минемуллина, А. Р. Ирония как средство имплицитного выражения оценки в языке средств массовой информации / А. Р. Минемуллина // Вестник Вятского гуманитарного государственного университета. - 2013. - № 2. - С. 17-21.

Негрышев, А. А. Стандарт и экспрессия в новостном медиатексте: к прагматике композиционной структуры / А. А. Негрышев // Меди@льманах. -2013. - № 2 (55). - С. 40-45.

Скороходова, Е. Ю. Ирония в современном медийном тексте / Е. Ю. Скороходова // Филологические науки. Язык, речь, речевая коммуникация. 2011. - № 7. - Электрон. текстовые дан. - Режим доступа: http://www.rusnauka.com/26_NII_2011/ Philologia/7_92393.doc.htm. - Загл. с экрана.

Скрипак, И. А. Экспрессивный синтаксис в текстах научного дискурса / И. А. Скрипак // Филологические науки. Вопросы теории и практики. 2013. - № 4 (22), Ч. II. - C. 170-173.
Хасанова, Н. Ф. Категория экспрессивности и ее соотношение с категориями интенсивности, эмоциональности, эмотивности и образности / Н. Ф. Хасанова // Научные исследования и разработки молодых ученых. - 2015. - Вып. 6. -С. 105-108.

Чиж, О. К. Речевые средства воздействия на общественное сознание: языковое манипулирование в СМИ / О. К. Чиж// Молодой ученый. -2012 . №3. - C. 282-284.

\section{ИСТОчНИКИ}

Интерфакс - Информационное агентство «Интерфакс-Украина». - Электрон. текстовые дан. - Режим доступа: http://interfax.com.ua/. - Загл. с экрана.

Укринформ - Украинское национальное информационное агентство. - Электрон. текстовые дан. - Режим доступа: http://www.ukrinform.ua/rus. Загл. с экрана.

УНИАН - Украинское независимое информационное агентство новостей.- Электрон. текстовые дан. - Режим доступа: http://www.unian.net/news/ 58. - Загл. с экрана.

УНН - Информационное агентство «Украинские национальные новости». - Электрон. текстовые дан. - Режим доступа: http://www.unn.com.ua/ $\mathrm{ru} /$. - Загл. с экрана.

\section{REFERENCES}

Arnold I.V. Interpretatsiya khudozhestvennogo teksta: tipy vydvizheniya i problemy ekspressivnosti [Interpretation of a Literary Text: Types of Extensions and Problems of Expressiveness]. Ekspressivnye sredstva angliyskogo yazyka: sb. nauchnykh trudov LGPI im. A. I. Gertsena [Expressive Means of the English Language: Collected Scientific Papers of LSPI named after A.I. Gertsen]. Leningrad, LGPI Publ., 1975, pp. 11-20.

Bessarabova N.D. Metafora i obraznost gazetnopublitsisticheskoy rechi [The Metaphor and Imagery of Journalese Speech]. Solganik G.Ya., ed. Poetika publitsistiki [The Poetics of Journalism]. Moscow, MGU Publ., 1990, pp. 21-34.

Voytenko K.I. Ekspressivnost kak semanticheskaya kategoriya [The Expressiveness as a Semantic Category]. Available at: www.rusnauka.com/ 13_EISN_2013/Philologia/2_132923.doc.htm.

Volf E.M. Funktsionälnaya semantika otsenki [Functional Semantics of Assessment]. Moscow, Nauka Publ., 1985. 228 p.

Gridin V.N. Ekspressivnost [Expressiveness]. Yartseva V.N., ed. Lingvisticheskiy entsiklopedicheskiy 
slovar [Linguistic Encyclopedic Dictionary]. Moscow, Sovetskaya entsiklopediya Publ., 1990. P 591.

Dronyaeva T.S. Informatsionnyy podstil [The Information Substyles]. Volodina M.N., ed. Yazyk SMI kak obyekt mezhdistsiplinarnogo issledovaniya [Media Language as an Object of Interdisciplinary Research]. Moscow, MGU Publ., 2003. Available at: http://evartist.narod.ru/text12/15.htm\#3_24.

Klushina N.I. Obshchie osobennosti publitsisticheskogo stilya [The Common Features of Journalism Style]. Volodina M.N., ed. Yazyk SMI kak obyekt mezhdistsiplinarnogo issledovaniya [Media Language as an Object of Interdisciplinary Research]. Moscow, MGU Publ., 2003. Available at: http:// evartist.narod.ru/text12/15.htm\#3_03.

Kudryavtseva L.A. Modelirovanie ekspressivno-pragmaticheskogo soderzhaniya $\mathrm{v}$ tekstakh gazetnoy kommunikatsii [Modelling of Expressive-Pragmatic Content of the Texts of Newspaper Communication]. Semantika yazykovykh edinits: dokl. VI Mezhdunar. konf. (Moskva, 1415 okt. 1998 g.) [The Semantics of Language Units: Reports of the $6^{\text {th }}$ International Conference (Moscow, October 14-15, 1998)]. Moscow, SportAkademPress, 1998, pp. 295-297.

Minemullina A.P. Adyektivnaya otsenochnaya leksika v zagolovke publitsisticheskogo teksta [The Adjective Evaluation Vocabulary in the Headline of the Journalism Text]. Yaroslavskiy pedagogicheskiy vestnik, 2014, vol. 1, no. 4, pp. 166-170.

Minemullina A.P. Ironiya kak sredstvo implitsitnogo vyrazheniya otsenki $\mathrm{v}$ yazyke sredstv massovoy informatsii [The Irony as a Means of Implicit Evaluation Expression in Mass Media Language]. Vestnik Vyatskogo gumanitarnogo gosudarstvennogo universiteta, 2013, no. 2, pp. 17-21.

Negryshev A.A. Standart i ekspressiya v novostnom mediatekste: $\mathrm{k}$ pragmatike kompozitsionnoy struktury [Standard and Expression in the News Media
Text: to the Pragmatics of Composite Structure]. Medi@lmanakh,2013,no.2(55),pp.40-45.

Skorokhodova E.Yu. Ironiya v sovremennom mediynom tekste [The Irony in the Modern Media Text]. Filologicheskie nauki, 2011, no. 7. Available at: http://www.rusnauka.com/26_NII_2011/Philologia/ 7_92393.doc.htm.

Skripak I.A. Ekspressivnyy sintaksis v tekstakh nauchnogo diskursa [The Expressive Syntax in Texts of Scientific Discourse]. Filologicheskie nauki. Voprosy teorii i praktiki, 2013, no. 4 (22), part 2, pp. 170-173.

Khasanova N. F. Kategoriya ekspressivnosti i ee sootnoshenie s kategoriyami intensivnosti, emotsionalnosti, emotivnosti i obraznosti [Category of Expressiveness and Its Relation to the Categories of Intensity, Emotionality, the Emotive and the Imaginative]. Nauchnye issledovaniya $i$ razrabotki molodykh uchenykh, 2015, iss. 6, pp. 105-108.

Chizh O.K. Rechevye sredstva vozdeystviya na obshchestvennoe soznanie: yazykovoe manipulirovanie v SMI [Speech Means of the Influence on the Public Consciousness: Language Manipulation in Mass Media]. Molodoy uchenyy, 2012, no. 3, pp. 282-284.

\section{SOURCES}

Informatsionnoe agentstvo "InterfaksUkraina» [Interfaks-Ukraina Information Agency]. Available at: http://interfax.com.ua/.

Ukrainskoe natsionalnoe informatsionnoe agentstvo [Ukrainian Independent Information Agency]. Available at: http://www.ukrinform.ua/rus.

Ukrainskoe nezavisimoe informatsionnoe agentstvo novostey [Ukrainian Independent News Agency]. Available at http://www.unian.net/news/58.

Informatsionnoe agentstvo «Ukrainskie natsionalnye novosti» [Ukrainian National News Information Agency]. Available at: http://www.unn. com.ua/ru/.

\section{Information About the Author}

Nadezhda M. Stetsenko, Candidate of Sciences (Philology), Associate Professor, Department of Russian and Ukrainian Languages, Donetsk National Technical University, Artema St., 58, 83001 Donetsk, stecenkon@ukr.net, http://orcid.org/0000-0003-4397-7877.

\section{Информация об авторе}

Надежда Михайловна Стеценко, кандидат филологических наук, доцент кафедры русского и украинского языков, Донецкий национальный технический университет, ул. Артема, 58, 83001 г. Донецк, stecenkon@ukr.net, http://orcid.org/0000-0003-4397-7877. 